Revista Brasileira de Meteorologia, v.29, n.2, 242 - 258, 2014

\title{
CONFIABILIDADE NAS ESTIMATIVAS DO REGIME DO VENTO FORNECIDAS PELO BRAMS NO ESTADO DE ALAGOAS: INFLUÊNCIA DO ANINHAMENTO E DA RESOLUÇÃO HORIZONTAL DE GRADES
}

\author{
LUCÍA IRACEMA CHIPPONELLI PINTO ${ }^{1}$, FERNANDO RAMOS MARTINS ${ }^{2}$, ENIO BUENO \\ PEREIRA ${ }^{1}$, GILBERTO FERNANDO FISCH ${ }^{3}$, ROBERTO FERNANDO DA FONSECA LYRA ${ }^{4}$ \\ ${ }^{1}$ Instituto Nacional de Pesquisas Espaciais, Centro de Ciência do Sistema Terrestre (INPE/CCST), São José \\ dos Campos, SP, Brasil \\ ${ }^{2}$ Universidade Federal de São Paulo, Campus Baixada Santista, Instituto do Mar, Santos, SP, Brasil \\ ${ }^{3}$ Instituto de Aeronáutica e Espaço, Departamento de Ciência e Tecnologia Aeroespacial (IAE/DCTA), São \\ José dos Campos, SP, Brasil \\ ${ }^{4}$ Universidade Federal de Alagoas, Departamento de Meteorologia (UFAL/CCEN), Maceió, AL, Brasil
}

lucia.chipponelli@inpe.br, fernando.martins@unifesp.br, enio.pereira@inpe.br, gfisch@iae.cta.br, roberto. ufal@gmail.com

Recebido Dezembro de 2012 - Aceito Setembro de 2013

\begin{abstract}
RESUMO
Os resultados do estudo comparativo entre os dados observados em duas torres anemométricas instaladas no estado de Alagoas, com estimativas de vento produzidas em simulações numéricas realizadas com o modelo de mesoescala BRAMS, são apresentados e discutidos com o intuito de investigar a influência do refinamento da resolução horizontal e do aninhamento de grades na confiabilidade das estimativas de vento. As torres estavam instaladas em regiões de características distintas do ponto de vista ambiental e climatológico. Análises estatísticas foram realizadas para avaliar o desempenho do modelo no que se refere à capacidade de fornecer estimativas de vento que reproduzam a evolução temporal, o ciclo médio diário e a distribuição de frequência do vento observado nas duas localidades. O estudo foi realizado para as duas estações sazonais características da região: estação chuvosa (Maio/2008) e seca (Novembro/2008). Os resultados mostraram que houve um aumento na confiabilidade das estimativas da velocidade do vento quando a resolução horizontal passou de $8 \mathrm{~km}$ para $2 \mathrm{~km}$. O ganho em confiabilidade foi mais significativo em Girau do Ponciano (GRP) localizada no interior do estado e que sofre menor influência do fenômeno de brisa marítima. $\mathrm{O}$ aumento da resolução horizontal para valores abaixo de $2 \mathrm{~km}$ não produziu redução importante dos desvios observados na estimativa da velocidade do vento pelo modelo na configuração adotada neste estudo. Os resultados demonstram a importância da aquisição de dados de campo para a investigação da confiabilidade, e ajuste das configurações e parametrizações inseridas em modelos numéricos, utilizados para estimar ou prever a disponibilidade de energia eólica em uma região específica.
\end{abstract}

Palavras-chave: Modelagem atmosférica, energia eólica, torre anemométrica.

ABSTRACT: RELIABILITY EVALUATION OF WIND REGIME ESTIMATES PROVIDED BY THE BRAMS MODEL FOR ALAGOAS STATE (BRAZILIAN NORTHEASTERN REGION): INFLUENCE OF NESTING AND HORIZONTAL RESOLUTION GRIDS.

Observational data obtained at two wind towers located at the Alagoas State (Northeast of Brazil NEB) were used to evaluate the influence of horizontal grid setup on the reliability of wind estimates provided by the numerical weather prediction model BRAMS. Statistical analysis were performed to evaluate the model skill in reproducing the temporal evolution, frequency distribution and the mean daily cycle of the wind observations in both locations. The study was performed for the two typical 
climate seasons: the rainy (May/2008) and the dry one (November/2008). The results demonstrated that the deviations of wind estimates gets lower if the horizontal grid resolution is increased from 8 $\mathrm{km}$ to $2 \mathrm{~km}$. No results improvement occurred when using horizontal grid resolution higher than 2 $\mathrm{km}$. The confiability on wind speed estimates were higher at Girau do Ponciano (GRP), located in the continental area where the sea breeze is less important to the atmospheric dynamic. The results demonstrate that wind data observations play an important role in defining the best configuration and parameterization model to better estimates the availability of wind energy on a specific region, particularly for NEB.

Keywords: Atmospheric modeling, wind power energy, wind mast.

\section{INTRODUÇÃO}

As fontes renováveis de energia vêm ganhando destaque nas duas últimas décadas em razão das preocupações ambientais decorrentes do crescimento das emissões de poluentes atmosféricos e aumento da concentração de Gases de Efeito Estufa (GEE) na atmosfera (Goldemberg e Villanueva, 2003; IPCC, 2011). O uso da energia eólica vem apresentando um crescimento destacado no Brasil desde 2002, em razão de uma série de benefícios no que tange a aspectos ambientais e sociais, amplamente discutidos em estudos realizados em âmbito nacional e internacional (Wilbanks et al., 2008; Brown, 2011; Martins e Pereira, 2011; Borba et al., 2012).

No entanto, o aproveitamento do recurso eólico necessita de um conhecimento apurado, tanto da disponibilidade desse recurso energético, quanto de sua variabilidade temporal, que está fortemente relacionado com as condições de tempo e clima em escalas regional e local. A confiabilidade da estimativa e da variabilidade do vento em um determinado local ou região de interesse é essencial, tanto para o desenvolvimento e avaliação da viabilidade econômica de uma planta eólica, quanto para o planejamento e gerenciamento do sistema de distribuição de eletricidade a que a planta eólica está conectada. Dessa forma, a ciência da Meteorologia pode contribuir de maneira relevante com o setor elétrico nacional em razão do conhecimento em modelagem atmosférica, da climatologia e dos sistemas meteorológicos que influenciam a circulação atmosférica na região de interesse.

A prospecção de áreas e regiões com elevado potencial técnico para a exploração comercial da energia eólica é realizada com o uso de modelos numéricos regionais, que demandam um investimento relativamente baixo (De Maria et al., 2008; Martins et al., 2008). A aplicação de modelos numéricos de mesoescala ou regionais, também pode ser utilizada para a previsão em curto e médio prazo do regime de vento, imprescindíveis para o planejamento da operação dos parques eólicos e do sistema de distribuição de energia (Martins et al., 2008; Monteiro et al., 2009).

Tanto a velocidade, quanto a direção do vento, são variáveis bastante difíceis de serem simuladas com precisão, devido ao fato de apresentar uma variabilidade grande no tempo e no espaço, em função da condição geográfica do local, da rugosidade da superfície associada ao relevo e à variabilidade da vegetação ou cobertura do solo ao longo do ano (Vendramini, 1986). Além disso, diversos outros fenômenos meteorológicos influenciam, de forma direta ou indireta, a dinâmica atmosférica no nordeste do Brasil (NEB). Dentre eles, podemos destacar, como exemplo desses fenômenos, o posicionamento da ZCIT (Zona de Convergência Intertropical), que influência de maneira direta a direção e intensidade dos ventos alísios, as anomalias na temperatura do Oceano Pacifico (Kayano e Andreoli, 2009), bem como, a passagem de Sistemas Frontais /Frentes Frias (SF), Vórtices Ciclônicos de Altos Níveis (VCANs) e Distúrbios Ondulatórios de Leste (DOLs), todos estes descritos, com detalhes, em Silva et al. (2011).

A confiabilidade das estimativas realizadas pelos modelos numéricos pode apresentar diferenças significativas em função das parametrizações e parâmetros físicos, como resolução espacial horizontal e vertical da grade, utilizados para a simulação dos processos físicos na atmosfera. A disponibilidade de uma base de dados confiável é essencial para planejamento e definição do projeto de uma planta eólica em uma área para a qual uma pré-avaliação do potencial foi realizada com o uso dos resultados dos modelos numéricos (Costa e Lyra, 2012). A base de dados observados contribui, tanto para o aprimoramento das parametrizações dos processos físicos, quanto para a determinação dos desvios e confiabilidade que o modelo apresenta para a área de estudo (Probst e Cárdenas, 2010). A aquisição da base de dados observados deve ser realizada de acordo com uma padronização estabelecida nacional ou internacionalmente (MEASNET, 2009; EPE, 2011). Entretanto, a execução de uma campanha de aquisição de dados de campo apresenta um custo de instalação, operação e manutenção muito elevado (Grubb e Meyer, 1993; Lira et al., 2011).

Alguns estudos já foram realizados para investigar a confiabilidade de modelos de mesoescala para a estimativa e previsão de vento para o NEB. Por exemplo, Lima et al. (2012) avaliou a capacidade do modelo BRAMS (Brazilian Regional Atmospheric Modeling System) em simular o vento a 10m acima do solo no Estado da Paraíba e verificou que o modelo obteve um desempenho satisfatório, tanto para o período chuvoso, quanto no período seco. Porém, o modelo apresentou dificuldade 
em reproduzir as variações devidas à fenômenos locais que possuem escala de tempo curta. De Maria et al. (2008) testou várias parametrizações disponíveis no modelo RAMS (Regional Atmospheric Modeling System) com o objetivo de avaliar o desempenho do modelo quando aplicado para o estado do Ceará. Dentre as opções testadas, a configuração que melhor reproduziu as observações de vento ao longo do litoral utilizou resolução horizontal de $1 \mathrm{~km}$, esquema de turbulência parametrizada por Smagorinsky e escala de tempo do relaxamento newtoniano de $12 \mathrm{~h}$.

Ramos et al. (2013) verificaram, em estudo com uso do modelo WRF (Weather Research and Forecasting) para o mapeamento do potencial eólico em Alagoas, que os menores desvios nas simulações da velocidade do vento ocorreram para o sertão e agreste alagoano, com erro médio inferior a $1 \mathrm{~m} . \mathrm{s}^{-1}$. As estimativas apresentaram menores desvios durante o seca (erro inferior a $0,5 \mathrm{~m} \cdot \mathrm{s}^{-1}$ ) e discrepâncias de até $3 \mathrm{~m} \cdot \mathrm{s}^{-1}$ foram obtidas para o período referente de chuva.

Sendo assim, o presente trabalho tem como objetivo compreender de que forma o aninhamento e a resolução horizontal de grades pode alterar a confiabilidade das estimativas de velocidade e direção do vento. O estudo é importante para compreender a aplicabilidade do modelo e para contribuir na definição de uma metodologia aplicada à previsão e estimativa dos ventos, que atenda e dê suporte às ações de planejamento e gerenciamento do sistema elétrico no país. A otimização de modelos numéricos para as regiões de interesse na exploração comercial da energia eólica deve crescer em importância, pois a participação desta fonte renovável na matriz elétrica brasileira deve crescer nos próximos anos (EPE, 2010).

\section{DADOS E METODOLOGIA}

Para este estudo, dois experimentos foram realizados para um período de 30 dias durante as estações seca (setembro a dezembro) e chuvosa (abril a julho) no estado de Alagoas, conforme Góis et al. (2005). Dados coletados em duas torres anemométricas localizadas em regiões distintas do estado (agreste e litoral) foram utilizados para avaliação da confiabilidade das estimativas. No primeiro experimento, o BRAMS foi configurado para uso de três grades com diferentes resoluções horizontais e com comunicação em duplo sentido entre si. O segundo experimento foi realizado com o BRAMS utilizando apenas uma grade horizontal.

\subsection{Caracterização e localização da área de estudo}

A área de estudo consiste no estado de Alagoas localizado no NEB entre as latitudes $08^{\circ} 48^{\prime} 47^{\prime \prime} S$ e $10^{\circ} 30$ '09'S e as longitudes $35^{\circ} 09^{\prime} 09^{\prime \prime} \mathrm{W}$ e $38^{\circ} 14^{\prime} 27^{\prime \prime} \mathrm{W}$. Possui uma área de 27.779 km² e seu território apresenta três mesorregiões: Agreste, Litoral e Sertão (Figura 1). A escolha dessa área se deve por dois aspectos principais:

i) $\mathrm{O}$ NEB é a região de maior potencial eólico no território nacional (Amarante et al., 2001; Silva et al., 2005; Pereira et al., 2008) e pode desempenhar um papel relevante no que tange a segurança energética do país, uma vez que estudos preliminares indicam a existência de complementaridade sazonal entre o recurso eólico e hidroelétrico, isto é, as maiores velocidades do vento foram observadas nos períodos em que o fluxo de água das bacias da região é mínimo (Pereira,2007);

ii) A disponibilidade de dados observados em torres anemométricas instaladas em acordo com a normatização internacional para coleta de dados para o setor energético.

Vários fenômenos meteorológicos atuam na região leste do NEB (ENEB) e afetam a circulação atmosférica, principalmente no estado de Alagoas. Dentre eles, podem-se citar as Perturbações Ondulatórias dos Alísios (POA); ZCIT, Sistemas Frontais (SF), anomalias na temperatura do Oceano Pacifico e o modo de variabilidade climática El Niño e La Niña.

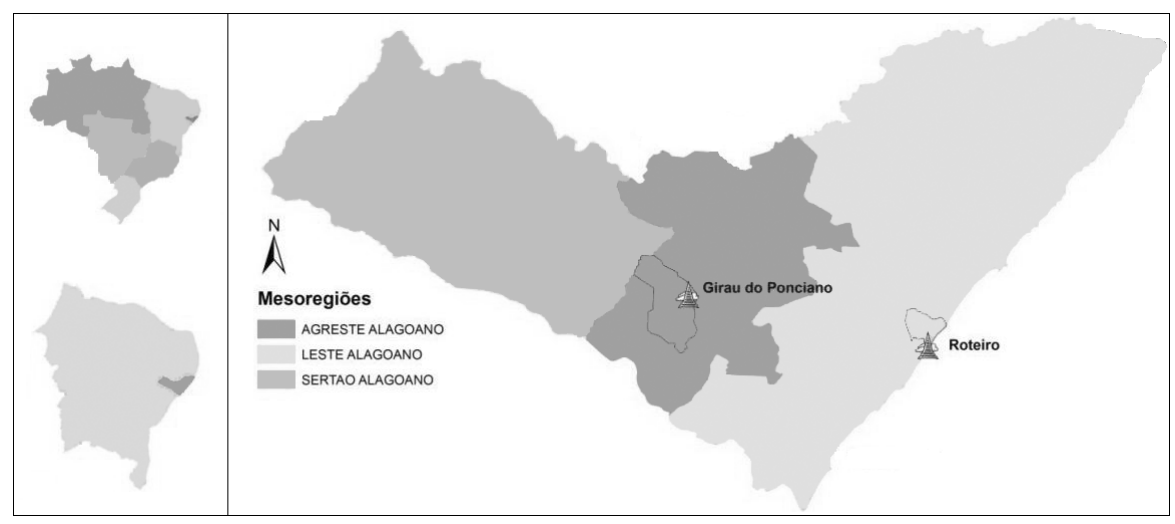

Figura 1 - Localização do Estado de Alagoas na região Nordeste do Brasil (NEB), com suas mesorregiões Agreste, Litoral e Sertão, respectivamente. Fonte: Ramos et al. (2013). 
Kayano e Andreoli (2009) afirmam que a dinâmica atmosférica do NEB é fortemente influenciada pelos Alísios, que, sobre a América do Sul (AS), são influenciados pelos centros de alta pressão no Atlântico Norte e Sul, cujas posições e intensidade se modificam sazonalmente. Durante a fase quente do El Niño - Oscilação Sul (ENOS), há uma intensificação da seca no semiárido nordestino e redução das chuvas na região costeira. Para a fase fria do ENOS, La Niña, a entrada de SF é mais frequente, pois há o aumento da magnitude do vento sobre o Pacífico equatorial, implicando na aceleração do deslocamento destas massas de ar para regiões mais próximas ao Equador (Molion e Bernardo, 2002). Os fenômenos de mesoescala como brisas montanha-vale, marítimas e terrestres também atuam de forma significativa em razão do relevo do estado.

\subsection{Dados anemométricos}

Foram utilizados dados de velocidade e direção de vento coletados em duas torres anemométricas: Roteiro (ROT: 09 56'29"S; 35 58'32"W; 40m) e Girau do Ponciano (GRP: $09^{\circ} 45^{\prime} 58^{\prime \prime} \mathrm{S} ; 36^{\circ} 47^{\prime} 06^{\prime \prime} \mathrm{W} ; 410 \mathrm{~m}$ ). As duas torres foram instaladas e operadas em parceria pela ELETROBRAS e UFAL para a realização do mapeamento eólico do estado. Anemômetros tipo concha classe I, modelo A100L2, e sensor de direção W200P (Vector Instruments) foram usados para medição da velocidade e direção do vento, respectivamente. Foram armazenados os valores médios das observações com resolução temporal de 10 min. A Figura 2 mostra a localização espacial das torres no território alagoano e uma descrição detalhada da configuração das torres anemométricas, bem como das características físicas locais estão apresentadas no Atlas Eólico do Estado de Alagoas (ELETROBRAS, 2008).

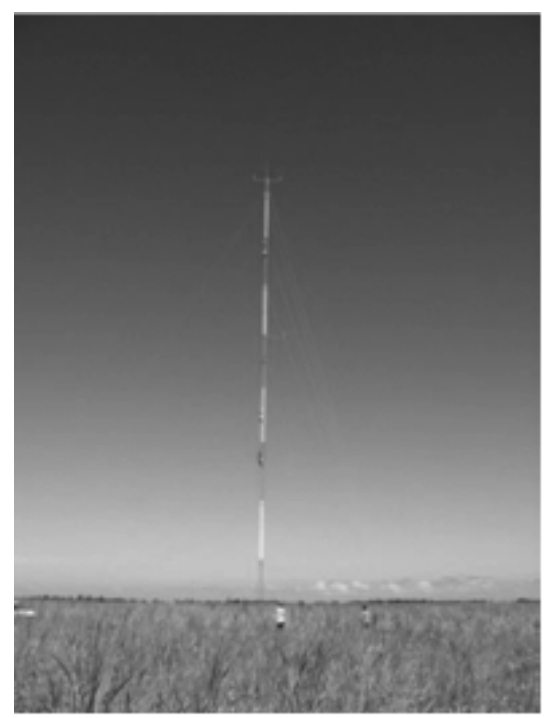

Neste estudo foram utilizados dados coletados a $50 \mathrm{~m}$ acima do solo durante os meses de maio e novembro de 2008. A escolha destes dois meses teve como finalidade a avaliação do desempenho do modelo nos períodos sazonais característicos da região em estudo: a estação chuvosa (abril a julho) e estação seca (setembro a dezembro), conforme Góis et al. (2005). A identificação de ocorrência de valores anômalos ocasionados por falhas instrumentais foi realizada com o uso do programa de controle de qualidade utilizado na rede SONDA (Sistema de Organização Nacional de Dados Ambientais). Os critérios adotados para a qualificação dos dados estão descritos em http:// sonda.ccst.inpe.br/infos/qualificacao.html.

\subsection{Modelo BRAMS}

As simulações numéricas realizadas neste estudo utilizaram a versão 4.2 do modelo de mesoescala BRAMS, desenvolvida por instituições brasileiras e internacionais com base na versão 6.0 do modelo RAMS. O modelo BRAMS possui parametrizações específicas para as condições atmosféricas tropicais, desenvolvidas com o intuito de aumentar a confiabilidade das simulações dos fenômenos meteorológicos observados no Brasil (Fazenda et al., 2007).

Para o desenvolvimento deste estudo, todas as simulações realizadas com o BRAMS utilizaram as seguintes parametrizações: o esquema de CARMA para os processos radiativos (Toon et al., 1989); o esquema de Grell e Devenyi (2002) para a convecção profunda; e a parametrização de convecção rasa desenvolvida e implementada por Souza (1999). O esquema de turbulência na Camada Limite Planetária (CLP) foi o esquema de Mellor e Yamada (1982) e a microfísica de nuvens segue o esquema descrito por Walko et al. (1995).

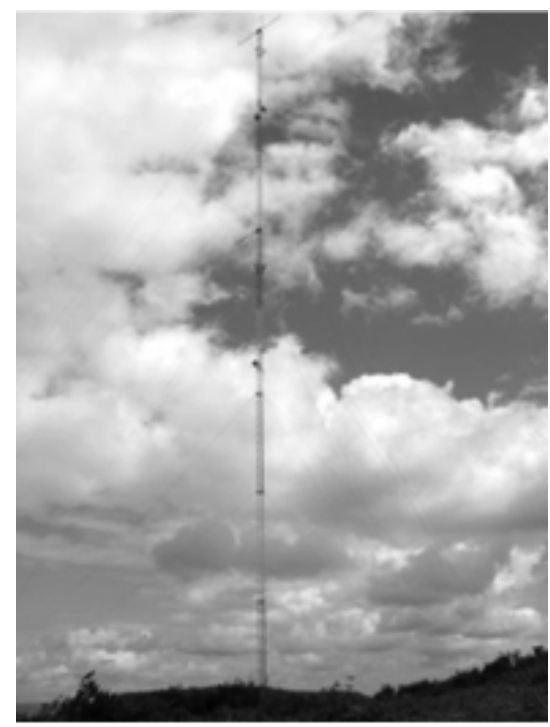

Figura 2 - Fotografias tiradas em campo das torres anemométricas e vegetação local. (a) ROT e (b) GRP. 
O modelo LEAF-3 (Walko et al., 2000) foi ativado para caracterização do uso e cobertura do solo. A resolução vertical usada consiste de 43 níveis com razão de alargamento (stretch ratio) de 1,2 e espaçamento máximo de $850 \mathrm{~m}$. Foram usadas nas simulações condições iniciais prescritas, TSM (Temperatura da Superfície do Mar) média semanal observada, dados de topografia com resolução espacial de $1 \mathrm{~km}$ e dados de textura do solo global (FAO, 1988).

Optou-se por inicializar o BRAMS com a base de dados de análises para 00 e 12 UTC do modelo regional Eta, que é executado operacionalmente CPTEC/INPE com resolução de $20 \mathrm{~km}$. A escolha por esta base de dados em detrimento do uso da base de dados globais do GFS teve como intuito utilizar uma base de dados regionalizada e mantida operacionalmente pelo INPE.

Inicialmente, as simulações foram realizadas utilizando três grades aninhadas com resoluções horizontais de $8 \times 8$ $\mathrm{km}, 2 \times 2 \mathrm{~km}$ e $500 \times 500 \mathrm{~m}$. As grades foram configuradas para permitir a interação em duplo sentido, permitindo que as simulações dos processos físicos da grade de maior resolução tenham influência nas simulações da grade de menor resolução e vice-versa (Souza, 2012). A Figura 3 apresenta a disposição das grades utilizadas na região de estudo e a Tabela 1 apresenta as informações das grades horizontais utilizadas. É importante destacar que apenas a localidade de GRP esta inserida na grade 3.

$\mathrm{O}$ modelo foi configurado de modo a permitir a comunicação em duplo sentido entre as grades aninhadas. As análises realizadas tiveram como objetivo principal investigar a confiabilidade das estimativas do vento e verificar se as estimativas obtidas nas grades com resolução horizontal mais refinada apresentariam desvios menores em relação aos valores observados em torres anemométricas. A opção pela comunicação em duplo sentido foi realizada pelo fato de os autores acreditarem que a comunicação entre as grades poderia contribuir para uma redução dos desvios entre os valores observados e estimados em cada uma das grades. Com o intuito de avaliar a influência do aninhamento de grades com interação em duplo sentido na confiabilidade das estimativas de velocidade do vento, foi realizado um experimento com a execução do BRAMS utilizando apenas a grade com resolução horizontal de $8 \mathrm{~km}$ x $8 \mathrm{~km}$ localizada na mesma posição da grade 1 (Tabela 1).

O BRAMS foi configurado para fornecer estimativas horárias de velocidade de vento a fim de permitir a comparação mais detalhada do ciclo diário do vento estimado e observado nas torres anemométricas. Com exceção da configuração espacial das grades e da resolução temporal adotadas neste estudo, todos os demais parâmetros e parametrizações foram selecionados com base na experiência adquirida na execução rotineira do BRAMS pelo CPTEC/INPE.

\subsection{Validação entre dados observados e as simulações (índices estatísticos)}

Neste trabalho, a confiabilidade das estimativas de velocidade do vento fornecidas pelo BRAMS foi avaliada

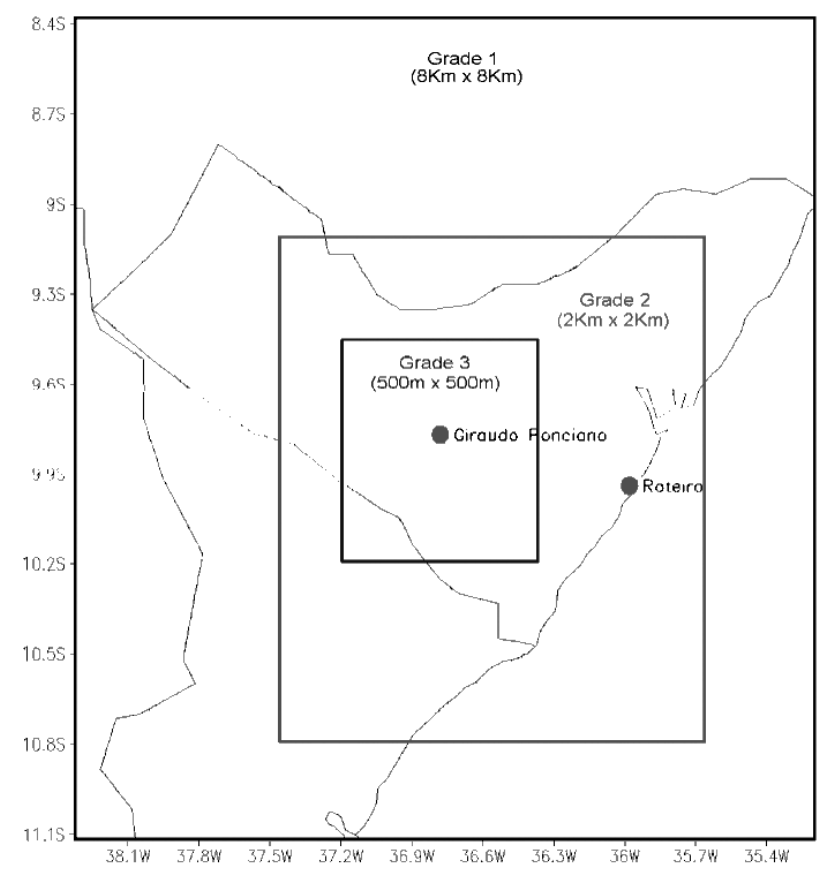

Figura 3 - Representação das grades horizontais usadas no modelo com suas respectivas resoluções e localização.

Tabela 1 - Especificações das grades horizontais usadas nas simulações do modelo BRAMS, onde Nx e Ny são os números de pontos existentes em cada grade, Dx e Dy a resolução (em km) de cada grade.

\begin{tabular}{|c|c|c|c|c|c|c|c|}
\hline ID. & $\begin{array}{c}\text { Resolução } \\
\text { Horizontal } \\
(\mathrm{m})\end{array}$ & $\begin{array}{c}\text { Latitude do } \\
\text { centro da } \\
\text { grade }\end{array}$ & $\begin{array}{c}\text { Longitude do } \\
\text { centro da } \\
\text { grade }\end{array}$ & $\begin{array}{c}\mathrm{N}_{\mathrm{x}} \\
(\# \mathrm{de} \\
\text { pontos })\end{array}$ & $\begin{array}{c}\mathrm{N}_{\mathrm{y}} \\
(\# \mathrm{de} \\
\text { pontos })\end{array}$ & $\begin{array}{c}\mathrm{D}_{\mathrm{x}} \\
(\mathrm{km})\end{array}$ & $\begin{array}{c}\mathrm{D}_{\mathrm{y}} \\
(\mathrm{km})\end{array}$ \\
\hline Grade 1 & 8000 & $9^{\circ} 45^{\prime} \mathrm{S}$ & $36^{\circ} 45^{\prime} \mathrm{W}$ & 45 & 45 & 8 & 8 \\
\hline Grade 2 & 2000 & $9^{\circ} 45^{\prime} \mathrm{S}$ & $36^{\circ} 45^{\prime} \mathrm{W}$ & 102 & 102 & 2 & 2 \\
\hline Grade 3 & 500 & $9^{\circ} 45^{\prime} \mathrm{S}$ & $36^{\circ} 45^{\prime} \mathrm{W}$ & 182 & 182 & 0,5 & 0,5 \\
\hline
\end{tabular}


por meio da comparação com os valores observados nas torres anemométricas. Foram utilizados os seguintes índices estatísticos: Erro Médio (EM) e a Raiz do Erro Médio Quadrático (REQM). Os índices foram calculados conforme descrito nas Equações 1 e 2 apresentadas abaixo, onde $\mathrm{P}_{\mathrm{i}}$ e $\mathrm{O}_{\mathrm{i}}$ representam, respectivamente, os valores estimados e observados da velocidade do vento. O EM é também conhecido como BIAS ou Viés e indica a ocorrência de superestimativa (valores positivos de EM) ou subestimativa (valores negativos de EM) da velocidade do vento observada nas torres anemométricas. O cálculo do REQM tem como objetivo avaliar a dispersão dos desvios apresentados pelas estimativas em relação aos valores observados.

$$
\begin{aligned}
& E M=\frac{1}{n} \sum_{i=0}^{n}\left(P_{i}-O_{i}\right) \\
& \text { REQM }=\sqrt{\frac{1}{n} \sum_{i=0}^{n}\left(P_{i}-O_{i}\right)^{2}}
\end{aligned}
$$

O coeficiente de correlação $(R)$ entre valores de velocidade de vento observadas nas torres e as estimativas do BRAMS também foi determinado. O valor de R é adimensional e pode variar de -1 a 1 e uma simulação perfeita apresentará coeficiente de correlação igual a 1. Entretanto, é possível ocorrer uma correlação elevada para dados das simulações dos modelos com erros muito grandes, isso se deve ao fato do coeficiente de correlação ser independente da escala e não levar em conta os desvios das estimativas (Wilks, 2011)

\section{RESULTADOS E DISCUSSÃO}

\subsection{Análise de desvios e evolução temporal do vento}

A Figura 4 apresenta a comparação da evolução temporal da velocidade do vento estimada e observada nas torres ROT e GRP, para o mês de Maio de 2008 (estação chuvosa). Observa-se que o BRAMS subestimou a velocidade do vento observado em ROT (Figura 4b), independentemente da resolução da grade horizontal utilizada (2 e $8 \mathrm{~km})$. Os valores mínimos estimados para a velocidade do vento foram muito menores

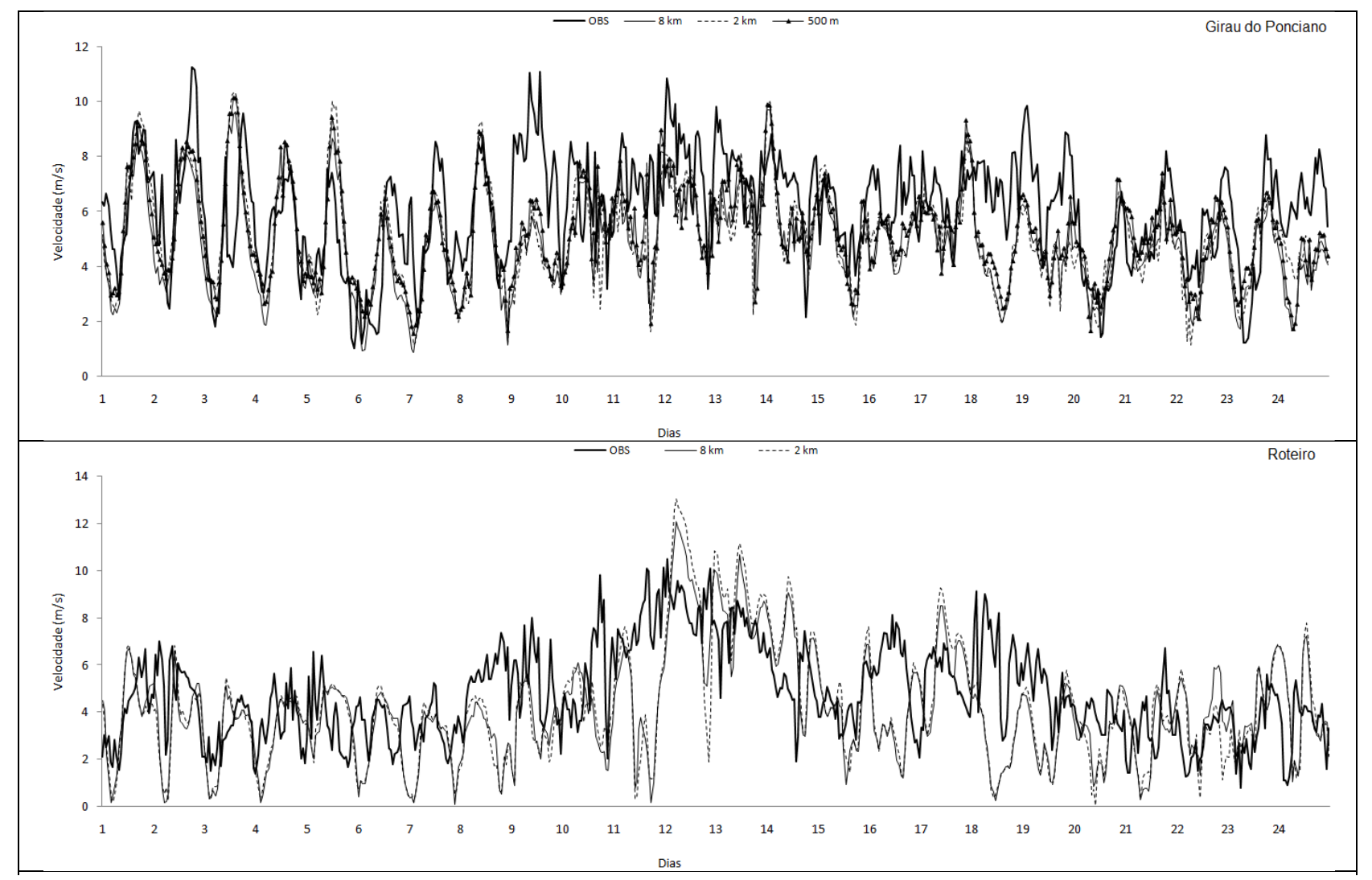

Figura 4 - Evolução temporal da velocidade do vento (em m/s) em Maio/2008 em Girau do Ponciano (a) e Roteiro (b). Os valores observados estão representados na linha preta forte. Os valores estimados nas Grades 1, 2 e 3 estão apresentados respectivamente pelas linhas cheia (8 km), pontilhada $(2 \mathrm{~km})$ e triângulos $(500 \mathrm{~m})$. 
que os mínimos observados pelo anemômetro instalado a $50 \mathrm{~m}$ acima do solo. Observa-se também, que aconteceram discrepâncias consideráveis em alguns períodos do mês, como, por exemplo, entre os dias 10 e 12, devido a passagem de um sistema ondulatório de Leste (Climanálise, 2008).

Nota-se ainda, na Figura 4, que o modelo BRAMS apresentou um comportamento similar no que se refere às estimativas de vento em GRP (Figura 4a) com ocorrência de períodos apresentando uma discrepância elevada entre valores estimados e observados da velocidade do vento. É importante destacar que há momentos em que a velocidade do vento prevista e a observada apresentam diferenças superiores a $6 \mathrm{~m} / \mathrm{s}$. Estas variações podem estar relacionadas a erros decorrentes da parametrização numérica inadequada dos processos físicos atuantes na atmosfera e das condições de contorno adotadas. Durante o mês de maio ocorrem chuvas frequentes decorrentes de diversos fenômenos atmosféricos (tais como influenciados por SF, DOL e/ou VCAN) que por sua vez podem estar sendo mal representados pela configuração do modelo BRAMS adotada neste estudo. Isso indica a necessidade de melhor compreender a influência das parametrizações selecionadas para a modelagem atmosférica, bem como, a eficiência dessas parametrizações para simular os processos físicos regionais e locais característicos que influenciam a velocidade e direção do vento na região de interesse.

O refinamento na resolução horizontal produziu redução significativa nos desvios apresentados pelas estimativas da velocidade do vento para o mês de Maio (Tabela 2). A maior redução foi observada para o EM, com redução entre $15 \%$ (em ROT) e $20 \%$ (em GRP) no aumento de resolução de $8 \mathrm{~km}$ para $2 \mathrm{~km}$. A redução do EM não refletiu em redução proporcional da REQM indicando que os desvios não são sistemáticos. $\mathrm{Na}$ verdade, o REQM apresentou comportamento dispare, sendo que houve uma redução de $2 \%$ em GRP e um crescimento de $3 \%$ em ROT. Isto pode estar associado a não representação de circulações de brisa (marítima e terrestre) pelo modelo.

A Tabela 2 indica que as estimativas de vento obtidas na grade 3, apenas para GRP, apresentaram uma redução de $30 \%$ no EM e de $8 \%$ do REQM em relação aos desvios observados para as estimativas de vento produzidas na grade 1 .

A Figura 5 mostra a evolução temporal para o mês de Novembro. Verifica-se que, tanto os valores observados, quanto os estimados da velocidade do vento são maiores que os valores referentes ao mês de Maio, fato esperado para esta época do ano (estação seca) na região (Costa e Lyra, 2012). Observa-se ainda que, o BRAMS subestimou a velocidade do vento em ambas as localidades e não conseguiu simular os eventos com maiores velocidade do vento. Assim como ocorreu no período chuvoso, o modelo BRAMS simulou uma frequência elevada de ventos muito fracos (velocidades inferiores a $3 \mathrm{~m} / \mathrm{s}$ ) para a localidade costeira (ROT) ao longo do período de estudo.

Na Figura 5, observa-se que houve um ganho (em torno de $0,5 \mathrm{~m} \cdot \mathrm{s}^{-1}$ ) no desempenho do BRAMS para as estimativas de vento em GRP, quando a resolução horizontal passou de 8 para $2 \mathrm{~km}$. O EM foi reduzido em 43\%, enquanto que o REQM foi reduzida em $20 \%$. No entanto, não houve redução dos desvios das estimativas de vento produzidas para ROT. A hipótese para essa diferença de comportamento do modelo está relacionada à influência da fenômeno de brisa marítima em ROT na região litorânea.

Ao contrário do observado na estação chuvosa, o uso da Grade $3(500 \mathrm{~m})$ não produziu uma redução dos desvios observados na estimativa da velocidade do vento para GRP. Na verdade, ocorreu um aumento de $22 \%$ e $7 \%$ dos valores de

Tabela 2 - Desvios estatísticos calculados para estimativas de velocidade do vento em GRP e ROT produzidas pelo modelo BRAMS configurado com três grades aninhadas. Os valores de REQM e EM estão apresentados em m/s. A torre anemométrica instalada em ROT não está inserida na área estabelecida para a Grade 3.

\begin{tabular}{|c|c|c|c|c|c|c|c|}
\hline \multirow[b]{2}{*}{ Período } & \multirow[b]{2}{*}{$\begin{array}{l}\text { Resolução } \\
\text { Horizontal }\end{array}$} & \multicolumn{3}{|c|}{ Girau do Ponciano (GRP) } & \multicolumn{3}{|c|}{ Roteiro(ROT) } \\
\hline & & $\begin{array}{c}\text { REQM } \\
(\mathrm{m} / \mathrm{s})\end{array}$ & $\begin{array}{c}\mathrm{EM} \\
(\mathrm{m} / \mathrm{s})\end{array}$ & $\mathrm{R}$ & $\begin{array}{c}\text { REQM } \\
(\mathrm{m} / \mathrm{s})\end{array}$ & $\begin{array}{c}\mathrm{EM} \\
(\mathrm{m} / \mathrm{s})\end{array}$ & $\mathrm{R}$ \\
\hline \multirow{3}{*}{$\begin{array}{l}\text { Estação Chuvosa } \\
\text { (Maio/2008) }\end{array}$} & $\begin{array}{c}8 \mathrm{~km} \\
(\text { Grade 1) }\end{array}$ & 2,15 & $-1,21$ & 0,54 & 2,45 & $-0,70$ & 0,38 \\
\hline & $\begin{array}{c}2 \mathrm{~km} \\
(\text { Grade } 2)\end{array}$ & 2,11 & $-0,98$ & 0,50 & 2,53 & $-0,59$ & 0,39 \\
\hline & $\begin{array}{c}500 \mathrm{~m} \\
(\text { Grade } 3)\end{array}$ & 1,97 & $-0,86$ & 0,53 & - & - & - \\
\hline \multirow{3}{*}{$\begin{array}{l}\text { Estação Seca } \\
\text { (Nov/2008) }\end{array}$} & $\begin{array}{c}8 \mathrm{~km} \\
(\text { Grade 1) }\end{array}$ & 2,68 & $-1,86$ & 0,52 & 2,18 & -1.41 & 0,54 \\
\hline & $\begin{array}{c}2 \mathrm{~km} \\
\text { (Grade 2) }\end{array}$ & 2,14 & $-1,06$ & 0,54 & 2,19 & $-1,39$ & 0,53 \\
\hline & $\begin{array}{c}500 \mathrm{~m} \\
\text { (Grade 3) }\end{array}$ & 2,29 & $-1,37$ & 0,57 & - & - & - \\
\hline
\end{tabular}




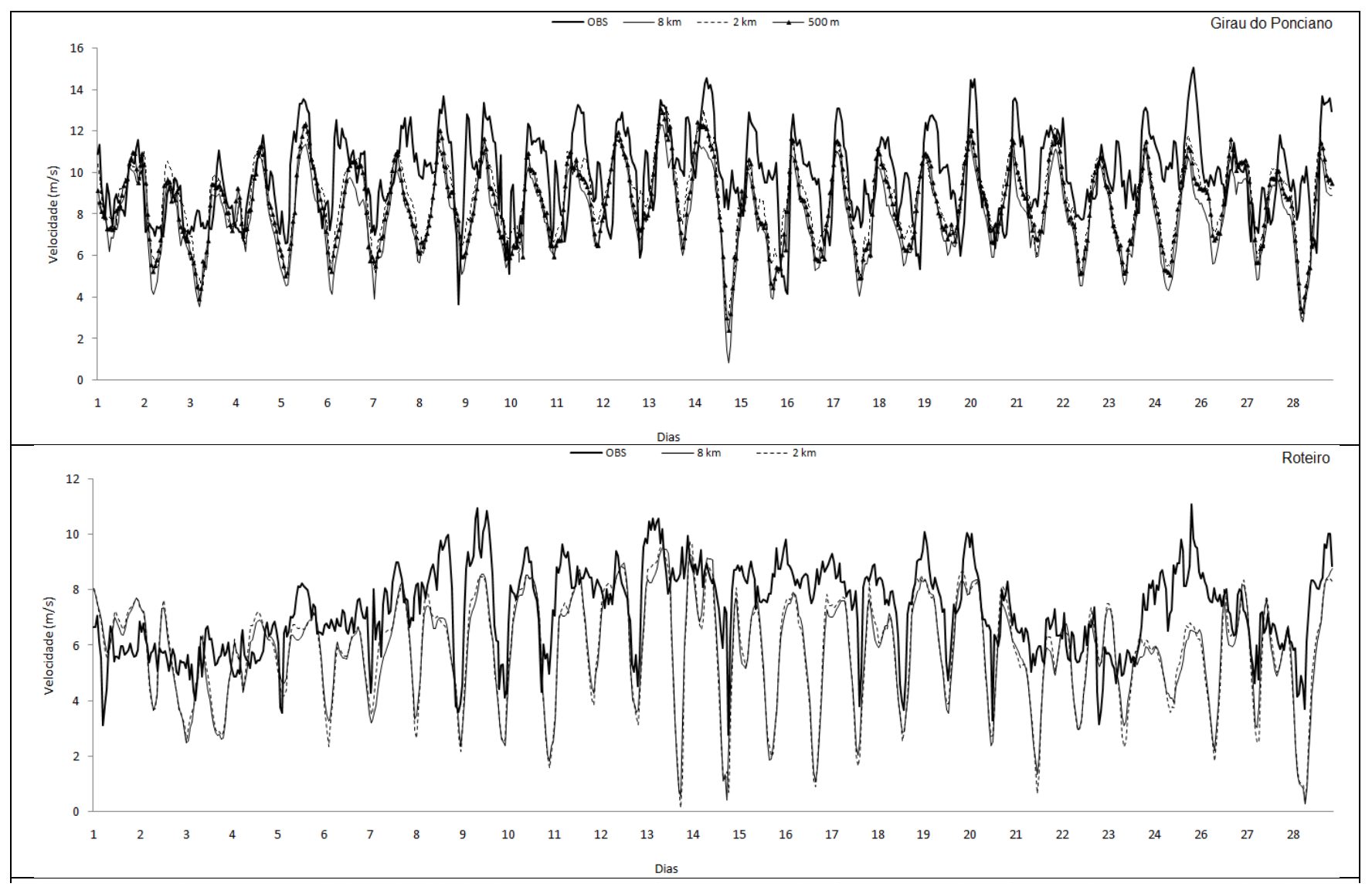

Figura 5 - Evolução temporal da velocidade do vento (em m/s) em Novembro/2008 em Girau do Ponciano (a) e Roteiro (b). Os valores observados estão representados na linha preta forte. Os valores estimados nas Grades 1, 2 e 3 estão apresentados respectivamente pelas linhas cheia (8 km), pontilhada $(2 \mathrm{~km})$ e triângulos $(500 \mathrm{~m})$.

EM e REQM, respectivamente, se comparado com os desvios observados na Grade $2(2 \mathrm{~km})$. A principal hipótese para esse crescimento dos desvios está relacionada com a representação inadequada da topografia na base de dados utilizada pelo modelo, uma vez que os processos físicos relacionados à convecção e microfísica são menos relevantes na dinâmica atmosférica durante a estação seca. Comparativamente, o modelo utilizou um valor de altitude de 0 (zero) $\mathrm{m}$ para a localidade litorânea, o que não é realístico uma vez que a torre em ROT está situada a uma altitude de $40 \mathrm{~m}$. Fato semelhante ocorre com a torre operando em GRP. As discrepâncias relativas ao relevo estão associadas à base de dados de topografia usados para alimentar o modelo e podem ser minimizadas com o uso de uma base de dados com resolução mais fina.

Os gráficos de dispersão, obtidos para localidade de ROT na estação chuvosa (Figura 6), mostram que as estimativas dos ventos mais intensos na região são em parte superestimadas e em parte subestimadas pelo BRAMS. A causa desse comportamento necessita ser investigada com o intuito de adequar as parametrizações adotadas no modelo para representação dos processos físicos que ocorre no ENEB. Para o mês da estação seca, o BRAMS subestimou o vento em praticamente todo o intervalo de velocidades observadas em ROT.

O desempenho do BRAMS referente às estimativas de vento para a localidade de GRP mostrou um comportamento similar nas duas estações do ano. Os ventos fortes (velocidades maiores que $6 \mathrm{~m} / \mathrm{s}$ )foram subestimados e os ventos fracos foram superestimados independente da resolução horizontal. Observando as Figuras 4 e 5, pode-se notar uma pequena defasagem temporal entre os instantes que os valores observados e estimados atingem os valores mínimos de velocidade do vento. Por essa razão, os valores de velocidade do vento inferiores a $6 \mathrm{~m} / \mathrm{s}$ se apresentam superestimados no gráfico de dispersão. Essa defasagem pode ser observada também na discussão sobre o ciclo diário médio discutido mais adiante neste trabalho.

\subsection{Direção do vento}

A Figura 7 apresenta a distribuição de frequência da direção simulada e observada dos ventos em ambas as torres nos meses de Maio e Novembro. Os resultados apresentados neste estudo estão em concordância com as análises realizadas 

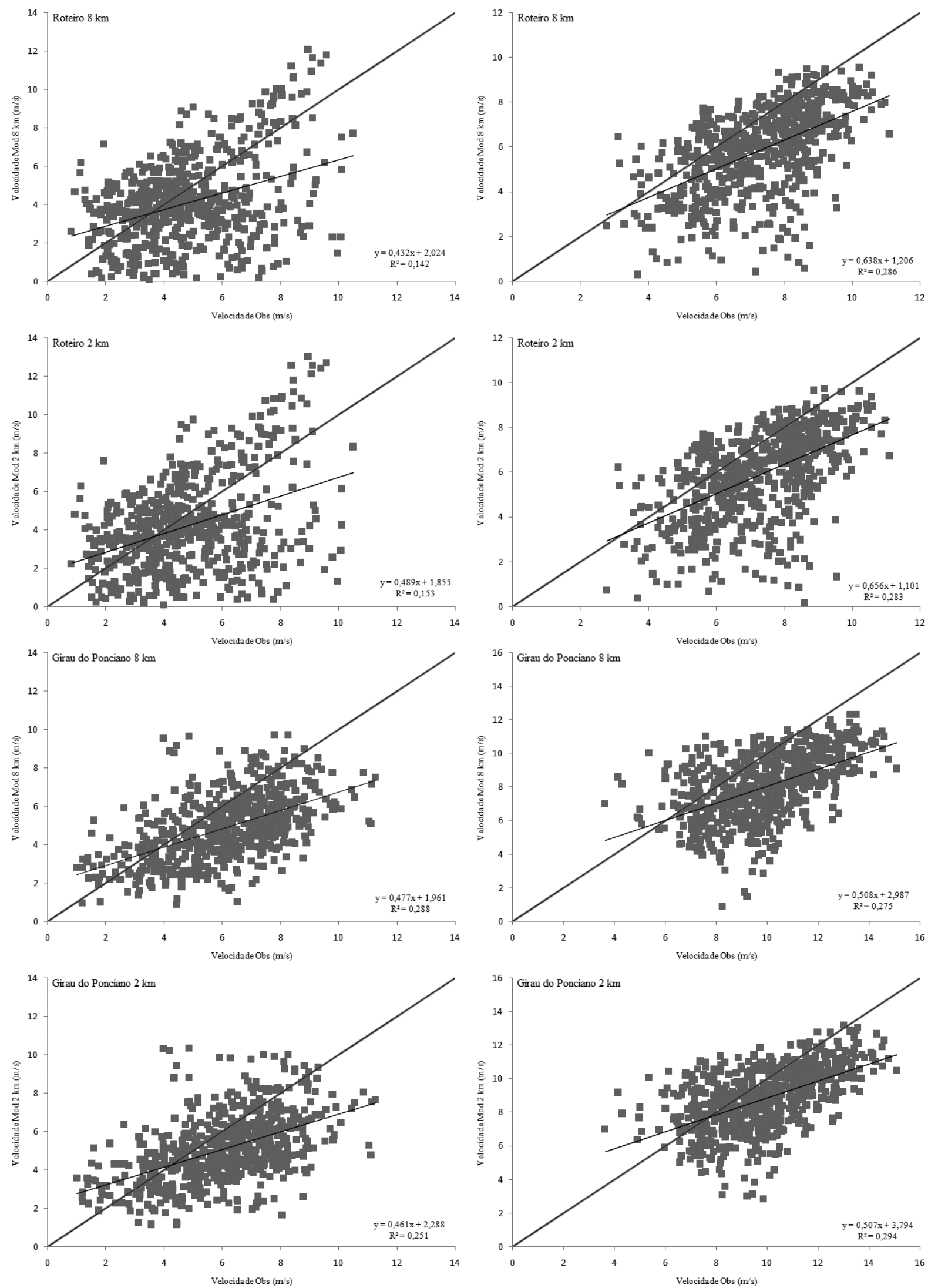

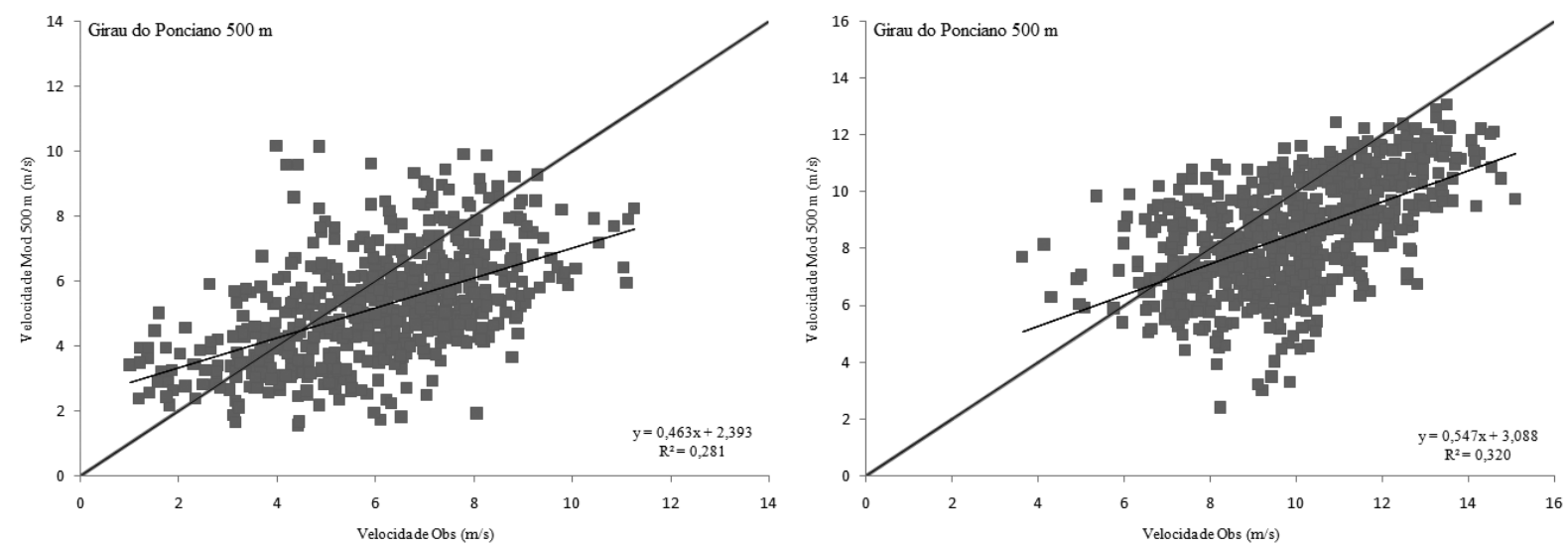

Figura 6 - Dispersão entre valores observados (torres) e estimados (BRAMS) da velocidade do vento (m/s) em Girau do Ponciano (GRP) e Roteiro (ROT) para os meses:(a) Maio e (b) Novembro.

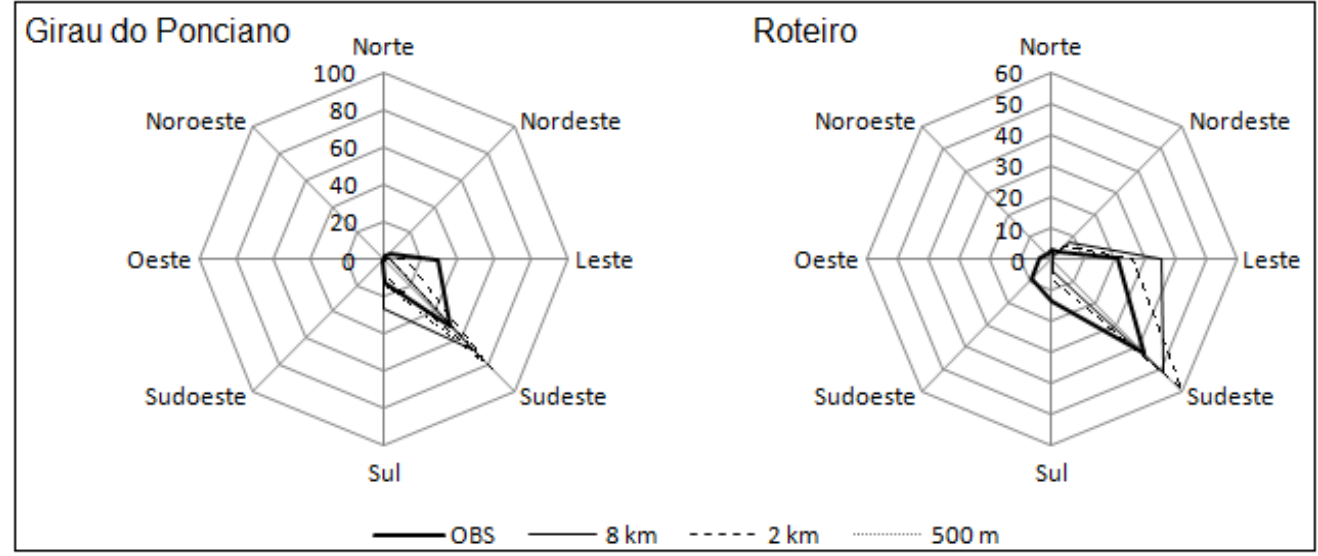

(a)

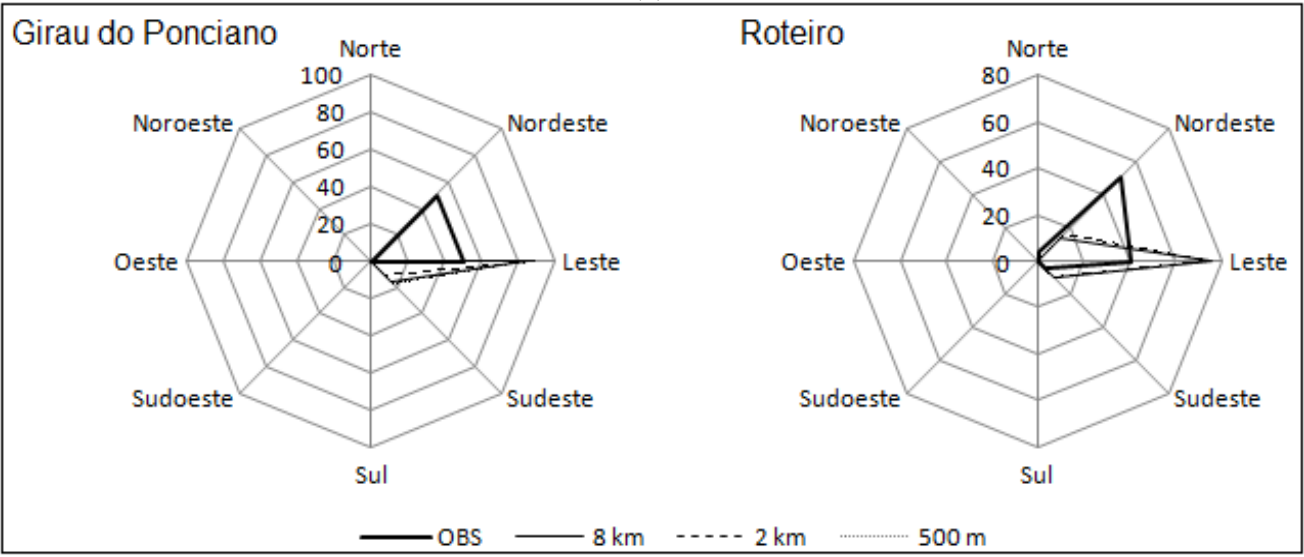

(b)

Figura 7 - Distribuição de frequência observada e estimada para a direção do vento $\left(^{\circ}\right)$ em Girau do Ponciano (GRP) e Roteiro (ROT) durante os meses: (a) Maio e (b) Novembro.

por Costa e Lyra (2012), que demonstraram a ocorrência de uma variabilidade da direção do vento entre as estações seca e úmida, tanto na região litorânea, quanto na agreste do estado. A alteração da direção predominante do vento entre o período seco e chuvoso já havia sido identificado também em estudos anteriores
(Amarante et al., 2001).A estimativa de direção do vento não foi influenciado de forma significativa pela resolução horizontal.

A Figura 7 mostra que as direções predominantes foram de E/SW para o vento estimado em ROT, demonstrando uma boa concordância com a observação registrada a $50 \mathrm{~m}$ acima do solo. 

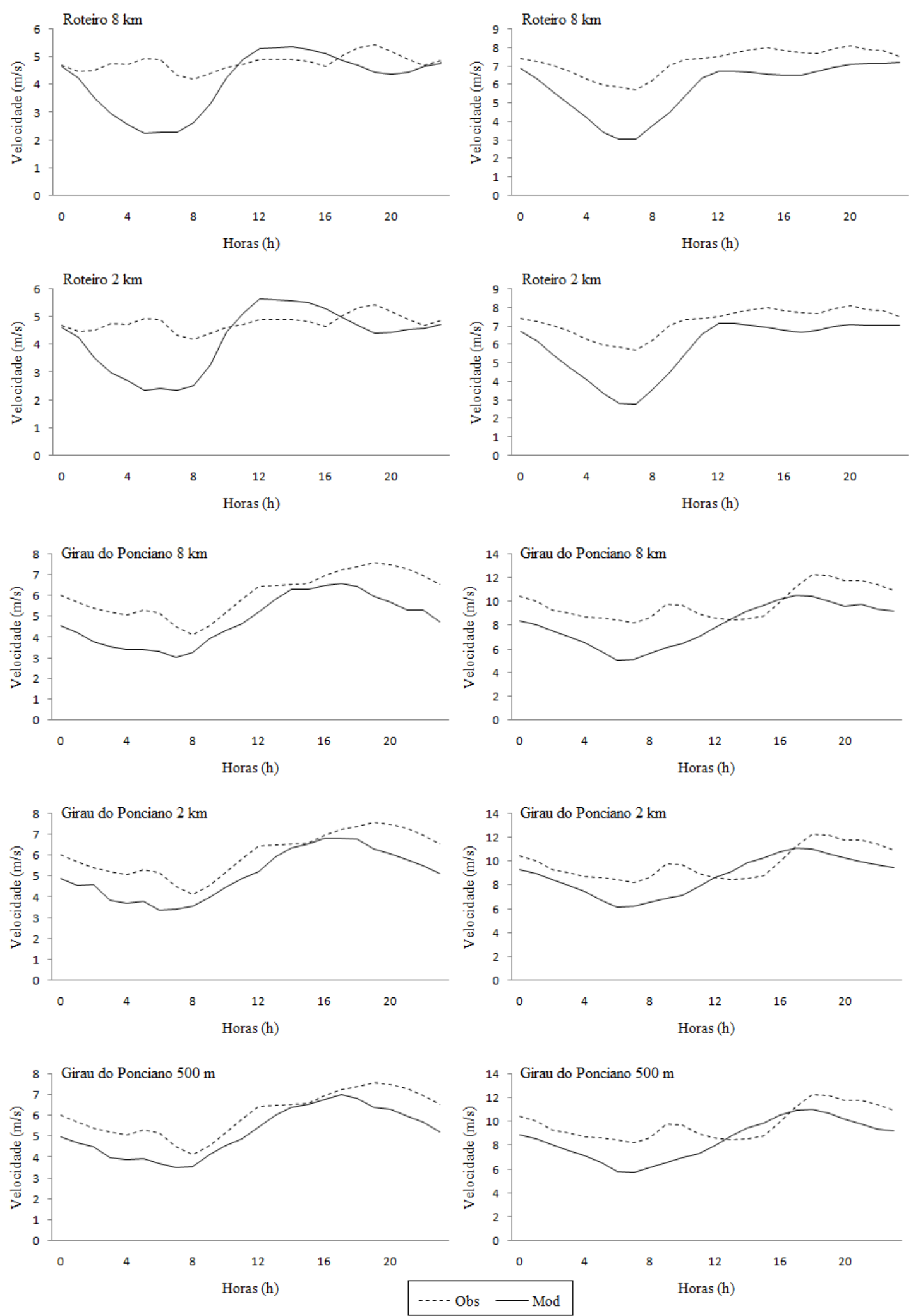

Figura 8 - Ciclo diário médio da velocidade do vento (m.s-1) em GRP e ROT para os meses: (a) Maio e (b) Novembro de2008. A linha sólida representa os valores observados e a linha pontilhada os valores estimados da velocidade do vento para as respectivas resoluções de grade $500 \mathrm{~m}$, $2 \mathrm{~km}$ e 8 km. 
Para a localidade de GRP, as direções estimadas e observadas predominantes foram E/SW. A concordância entre valores estimados e observados foi maior para esta torre localizada na região agreste do estado.

Em Novembro, estação seca, a direção predominante observada em ambas torres anemométricas foram de NW/E (Figura 7b). O modelo BRAMS estimou a maior frequência dos ventos nas direções E/SW para GRP e nas direções NE/E/ SW em ROT.

\subsection{Ciclo Diário}

O desempenho do modelo BRAMS em representar o ciclo diário médio também foi analisado para as duas estações (seca e chuvosa), em ambas as localidades, utilizando as estimativas obtidas em cada uma das grades (Figura 8).

A influência dos ventos alísios é muito forte no litoral do NEB e o padrão do vento é bastante uniforme no decorrer do dia, conforme constatado pelas medidas realizadas na torre anemométrica em ROT. Os dados observados na região do agreste do estado (GRP) apresentam um ciclo diário mais acentuado com ventos mais intensos ao fim da tarde e durante à noite, devido a influência do aquecimento da superfície. Este local, GRP, está distante da costa e sofre mais os efeitos do ciclo diurno. Estes resultados estão em acordo com os estudos desenvolvidos por Costa e Lyra (2012) e Ramos et al. (2013).

Para a localidade de ROT, o BRAMS subestima a velocidade do vento nas primeiras horas do dia para os 2 meses analisados neste trabalho, porém os desvios observados foram maiores no mês de Maio. Este fato é observado claramente nas Figuras 4 e 5.

A Figura 9 apresenta a comparação do ciclo diário do vento para três dias do mês de Maio escolhidos arbitrariamente, sendo um no inicio da simulação, outro no meio e o terceiro no final da simulação. O modelo BRAMS conseguiu simular a velocidade de vento em boa concordância com os valores observados no primeiro dia do mês de Maio em ROT. No entanto, para os demais dias, ele retardou o horário do dia em que o vento atinge seu maior valor e subestimou a velocidade do vento durante a madrugada. Em geral, o modelo simula melhor o ciclo diário em GRP indicando mais uma vez que os resultados do modelo apresentam desvios menores para a torre situada distante do litoral e com menor influência da circulação de brisa marítima. Nesta análise ficou claro que o modelo

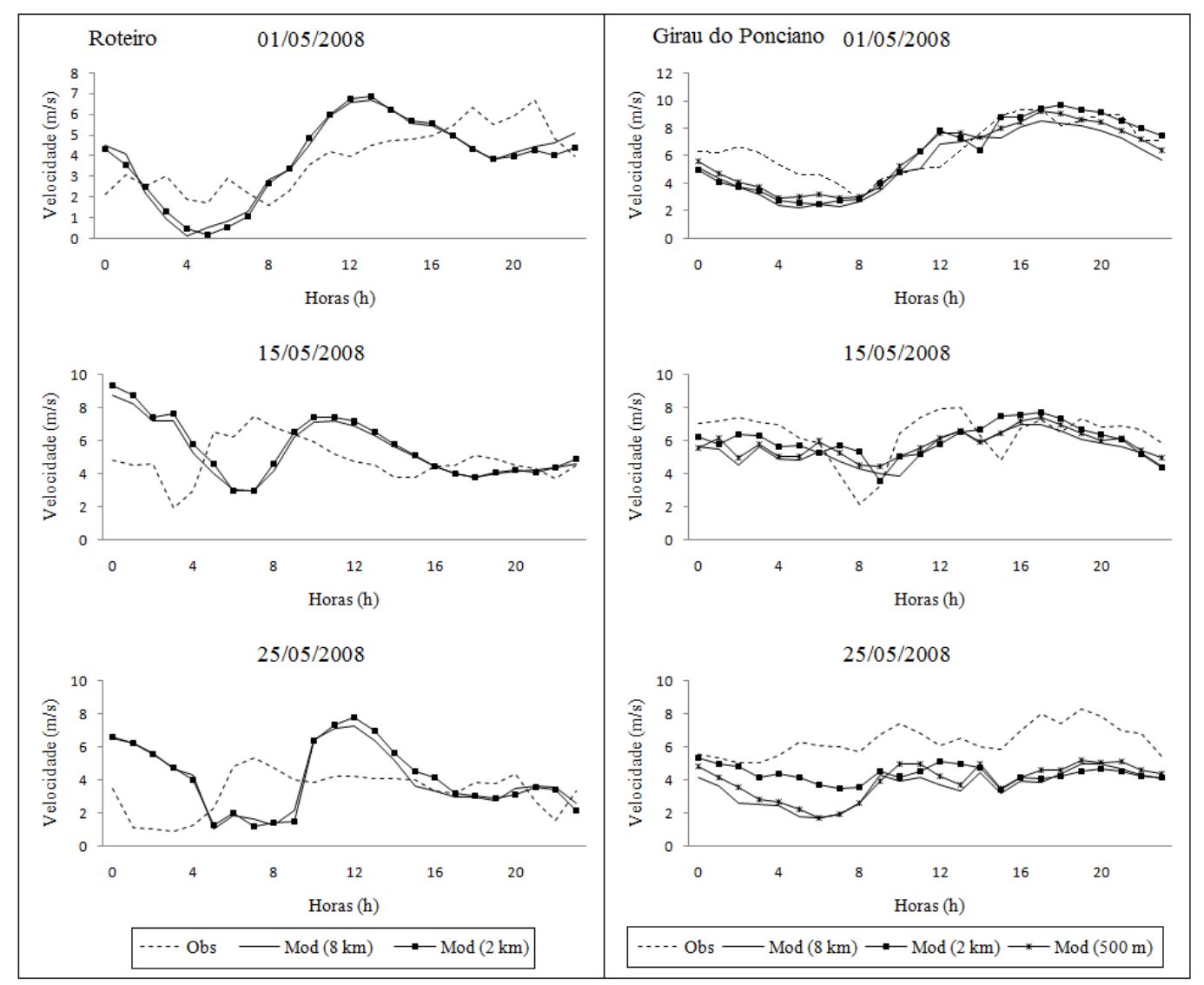

Figura 9 - Ciclo diário da velocidade do vento $(\mathrm{m} / \mathrm{s})$ para três dias aleatórios do mês maio: (a) Roteiro e (b) Girau do Ponciano, respectivamente. 


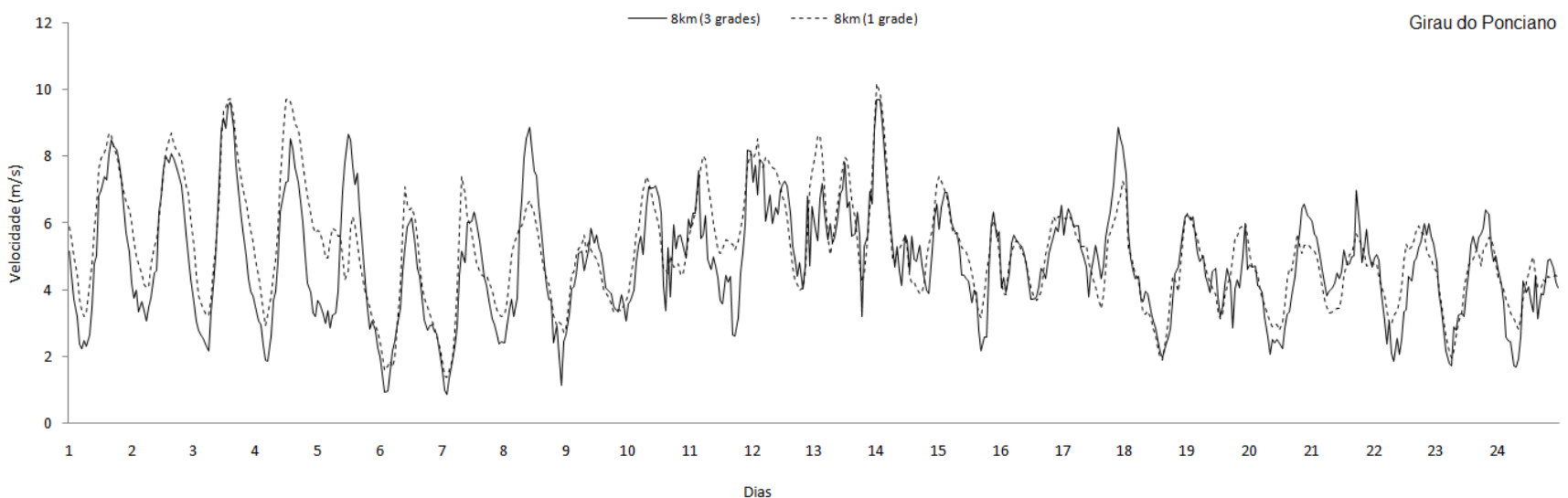

(a)

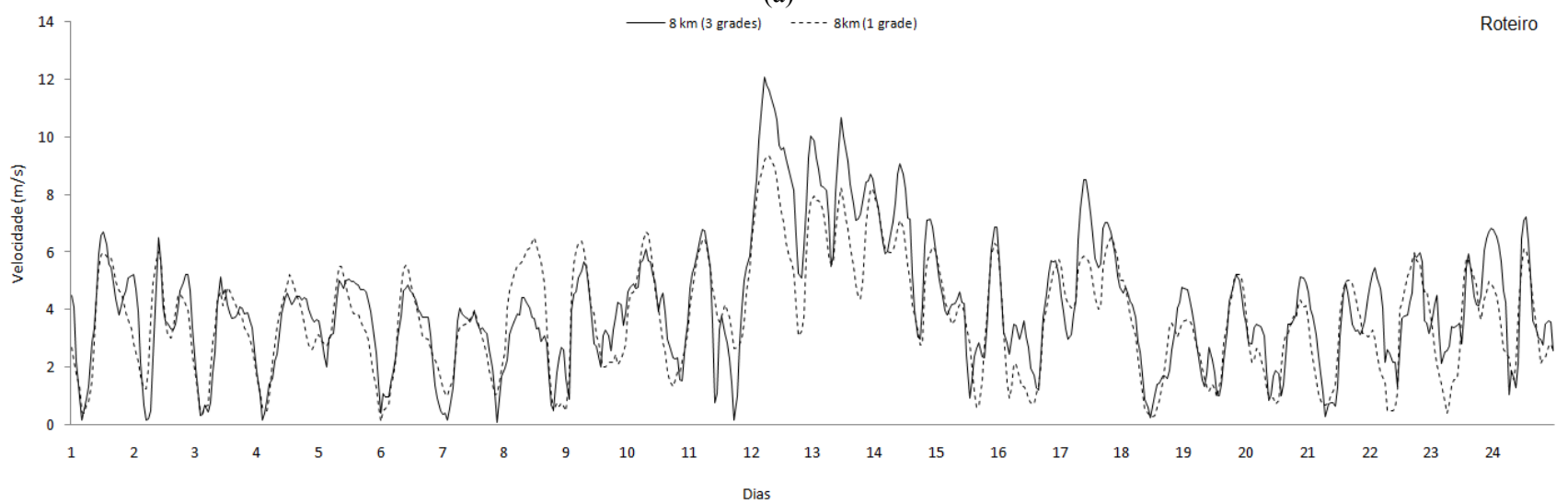

(b)

Figura 10 - Evolução temporal das estimativas de velocidade do vento (em m/s) para Maio/2008 em Girau do Ponciano (a) e Roteiro (b). As estimativas representadas na linha cheia foram obtidas na Grade $1 \mathrm{com}$ resolução horizontal de $8 \mathrm{~km}$ com o modelo BRAMS configurado com aninhamento de 3 grades com interação em duplo sentido. As estimativas representadas na linha pontilhada foram obtidas com o modelo BRAMS configurado com uma única grade com resolução horizontal de $8 \mathrm{~km}$.

BRAMS apresenta melhor desempenho na simulação do ciclo diário do vento em GRP.

\subsection{Influência do aninhamento de grades nas estimativas do vento}

Os resultados apresentados nos tópicos anteriores mostraram uma análise comparativa de valores observados de velocidade e direção do vento, com as estimativas obtidas com o BRAMS executado utilizando três grades aninhadas fixas (Tabela 1).

Com o intuito de investigar o papel desempenhado por esse aninhamento de grade na confiabilidade das estimativas, o segundo experimento foi realizado para comparar as estimativas de vento produzidas pelo modelo BRAMS, utilizando apenas uma grade com resolução horizontal de $8 \mathrm{~km}$ x $8 \mathrm{~km}$, posicionada da mesma forma que a grade 1 descrita na Tabela 1, com os resultados alcançados no experimento anterior. Conforme descrito na metodologia, este experimento utilizou a mesma configuração de parametrizações e bases de dados de entrada, de topografia, de vegetação, etc. utilizado no experimento anterior.

As Figuras 10 e 11 mostram a evolução temporal das estimativas obtidas neste experimento com uma única grade e as estimativas obtidas na Grade $1(8 \mathrm{~km})$ do experimento com grades aninhadas para os meses de Maio e Novembro de 2008, respectivamente. A Figura 12 apresenta a dispersão entre as estimativas produzidas pelas mesmas grades para os dois períodos do estudo. Fica claro a partir da análise dos gráficos apresentados, que o uso de uma única grade produziu estimativas de ventos mais (menos) intensos em GRP (ROT), tanto no mês correspondente à estação seca, quanto no mês chuvoso. A Tabela 3 apresenta os desvios das estimativas com relação aos valores observados em ROT e GRP.

Pode-se notar que o uso de uma única grade reduziu os desvios das estimativas de vento no agreste alagoano de forma significativa. O EM foi reduzido em $10 \%$ no mês de Maio e 32\% em Novembro. No que se refere ao REQM, o 


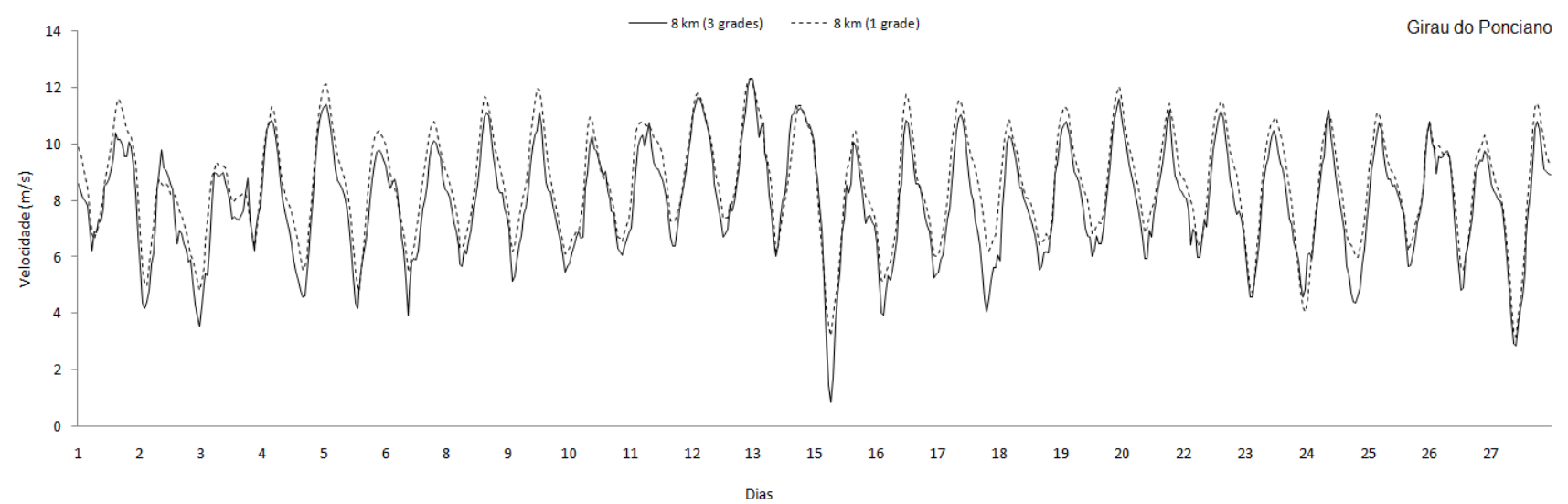

(a)

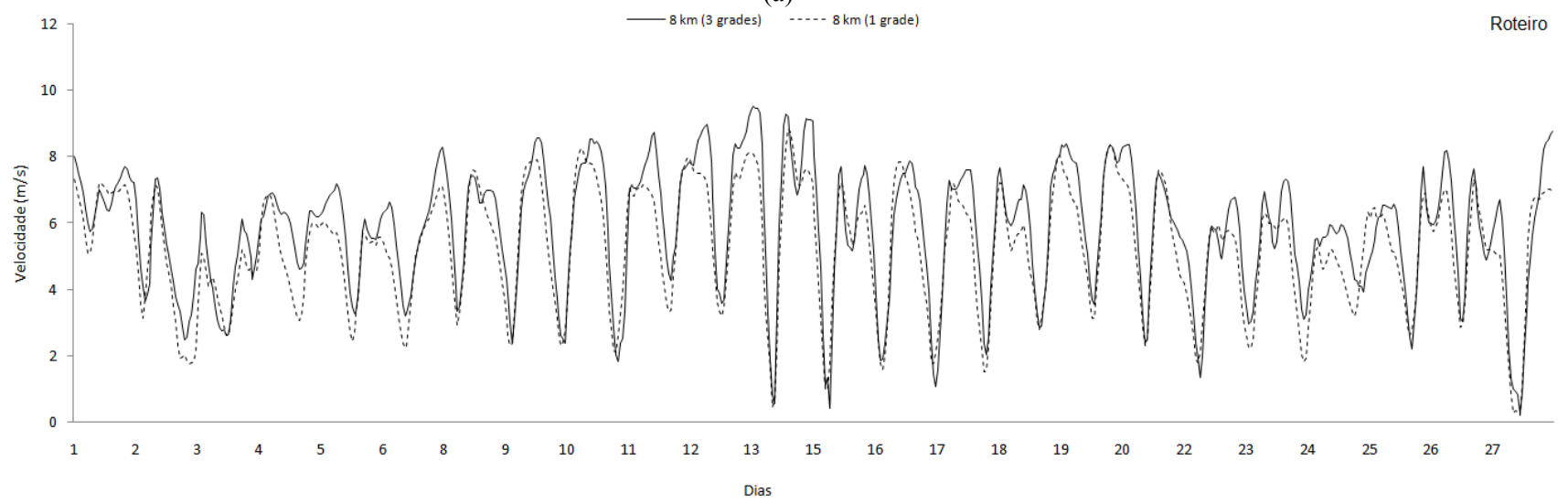

(b)

Figura 11 - Evolução temporal das estimativas de velocidade do vento (em m/s) para Novembro/2008 em Girau do Ponciano (a) e Roteiro (b). As estimativas representadas na linha cheia foram obtidas na Grade 1 com resolução horizontal de 8 km com o modelo BRAMS configurado com aninhamento de 3 grades com interação em duplo sentido. As estimativas representadas na linha pontilhada foram obtidas com o modelo BRAMS configurado com uma única grade com resolução horizontal de $8 \mathrm{~km}$.

Tabela 3 - Índices estatísticos comparando o desempenho do modelo BRAMS quando configurado com três grades aninhadas e quando configurado com apenas uma grade horizontal. Os valores de REQM e EM estão apresentados em m/s para as grades com resolução horizontal de 8 km.

\begin{tabular}{|c|c|c|c|c|c|c|c|}
\hline \multirow[b]{2}{*}{ Período } & \multirow[b]{2}{*}{$\begin{array}{l}\text { Resolução } \\
\text { Horizontal }\end{array}$} & \multicolumn{3}{|c|}{ Girau do Ponciano (GRP) } & \multicolumn{3}{|c|}{ Roteiro (ROT) } \\
\hline & & $\begin{array}{c}\text { REQM } \\
(\mathrm{m} / \mathrm{s}) \\
\end{array}$ & $\begin{array}{c}\mathrm{EM} \\
(\mathrm{m} / \mathrm{s}) \\
\end{array}$ & $\mathrm{R}$ & $\begin{array}{c}\text { REQM } \\
(\mathrm{m} / \mathrm{s}) \\
\end{array}$ & $\begin{array}{c}\text { EM } \\
(\mathrm{m} / \mathrm{s})\end{array}$ & $\mathrm{R}$ \\
\hline \multirow{2}{*}{$\begin{array}{l}\text { Estação Chuvosa } \\
\text { (Maio/2008) }\end{array}$} & $\begin{array}{c}8 \mathrm{~km} \\
\text { (Grades Aninhadas) }\end{array}$ & 2,15 & $-1,21$ & 0,54 & 2,45 & $-0,70$ & 0,38 \\
\hline & $\begin{array}{c}8 \mathrm{~km} \\
\text { (Grade única) }\end{array}$ & 2,13 & $-1,09$ & 0,49 & 2,45 & $-1,01$ & 0,34 \\
\hline \multirow{2}{*}{$\begin{array}{l}\text { Estação Seca } \\
\text { (Nov/2008) }\end{array}$} & $\begin{array}{c}8 \mathrm{~km} \\
\text { (Grade aninhadas) }\end{array}$ & 2,68 & $-1,86$ & 0,52 & 2,18 & -1.41 & 0,54 \\
\hline & $\begin{array}{c}8 \mathrm{~km} \\
\text { (Grade única) }\end{array}$ & 2,33 & $-1,27$ & 0,50 & 2,68 & $-2,11$ & 0,54 \\
\hline
\end{tabular}

desvio não apresentou uma redução importante durante o mês chuvoso (Maio), mas sofreu uma redução de $13 \%$ em Novembro (período seco) em GRP. Com base nos resultados obtidos neste estudo, o aninhamento de grades não trouxe benefícios para a confiabilidade das estimativas na região agreste. Porém, deve-se ter em mente que os resultados alcançados podem ter uma influência importante da resolução da base de dados de topografia utilizada para alimentar o modelo BRAMS.

No entanto, o uso de uma única grade produziu estimativas com desvios maiores em ROT na região litorânea. 

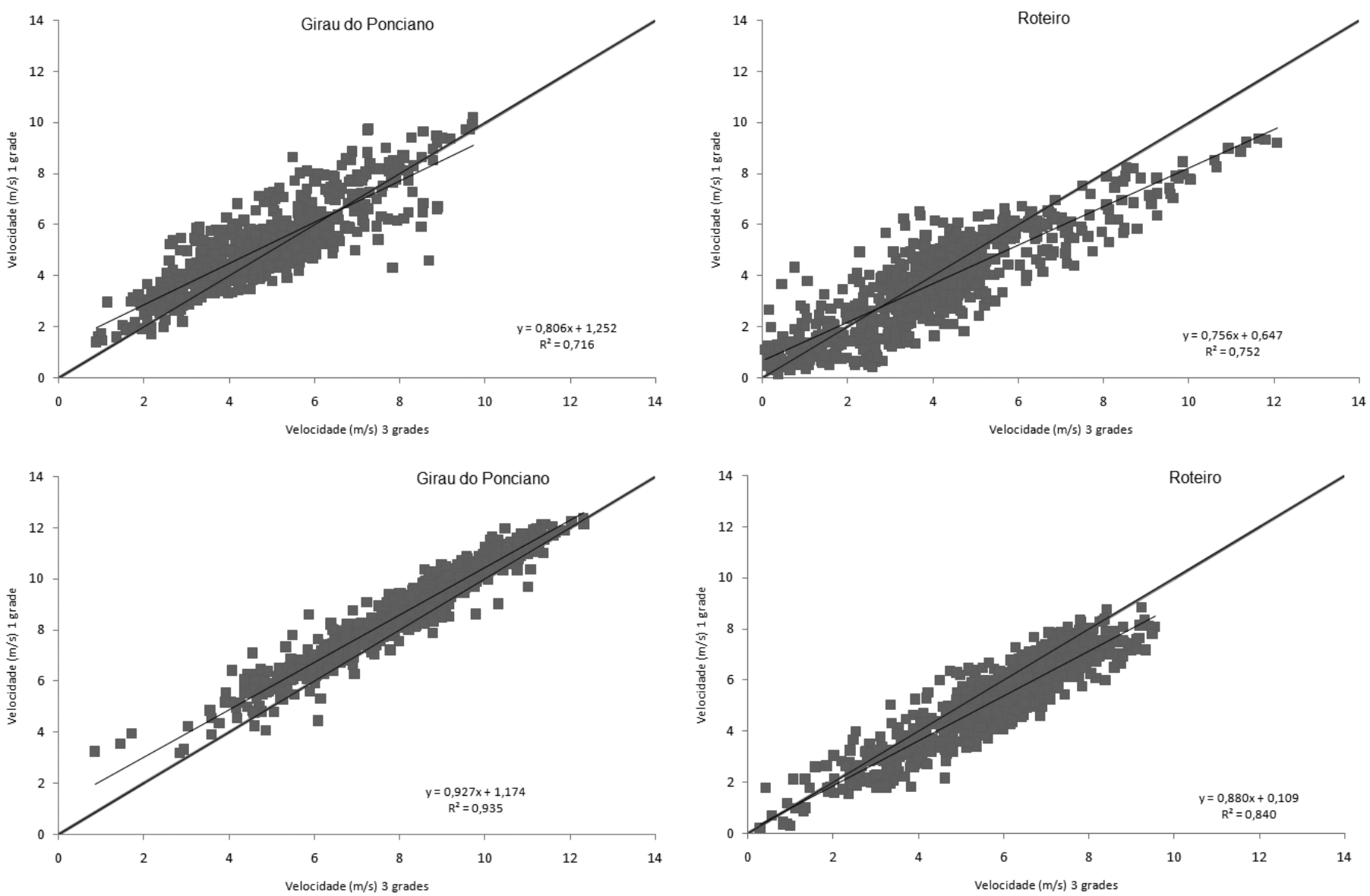

Figura 12 - Gráficos de dispersão entre as estimativas de velocidade de vento obtidas nas grades com resolução horizontal de 8 km x 8 km quando o modelo BRAMS foi configurado com grade única (eixo das ordenadas) e com três grades aninhadas (eixo das abcissas): (a) resultados referentes ao mês de Maio; (b) resultados referentes ao mês de Novembro.

O EM cresceu cerca de $45 \%$ considerando período seco e chuvoso, enquanto que REQM cresceu $23 \%$ apenas no mês de Novembro (seco). O uso de grades aninhadas com comunicação em duplo sentido aumentou a confiabilidade das estimativas de vento para a região litorânea obtidas com o modelo BRAMS na configuração adotada neste estudo.

Em resumo, o uso de aninhamento de grade não possibilitou uma melhor simulação dos processos físicos locais que influenciam a velocidade e direção do vento em GRP. Entretanto, este aninhamento de grade produziu um benefício na região litorânea, apesar de os resultados descritos nos tópicos anteriores indicarem a necessidade de adequação da configuração do modelo, no que se refere ao aprimoramento da base de dados de topografia e à definição das parametrizações numéricas adotadas para a simulação dos fenômenos de escala local e regional.

\section{CONCLUSÕES}

O estudo demonstra que há um aumento da confiabilidade das estimativas da velocidade e direção do vento, com o refinamento da resolução horizontal na região agreste do estado indicado de forma clara pelos valores, obtidos para o erro médio (EM) e para a raiz do erro quadrático médio (REQM). Este fato não foi evidente na região litorânea, onde houve uma pequena redução apenas do EM.

O ciclo diário médio das estimativas de velocidade do vento apresentaram boa concordância com o ciclo diário médio das observações realizadas em Girau do Ponciano no agreste do estado. No entanto, para a região costeira em Roteiro, o ciclo diário médio das estimativas apresentou discrepâncias significativas, principalmente nos períodos da madrugada e início da manhã. Fenômenos locais como a circulação de brisa marítima são hipóteses consideradas para explicar as discrepâncias observadas. Além disso, existe a necessidade de refinar a base de dados de topografia para melhor representar o relevo local. Neste estudo observou-se que o modelo atribuiu um valor de altitude de 0 (zero) $\mathrm{m}$ para o ponto de grade onde a torre em Roteiro está situada, sendo que a altitude correta da torre é $40 \mathrm{~m}$.

O aninhamento de grades é importante para a redução dos desvios apresentados pelas estimativas das velocidades de 
vento na região litorânea. Espera-se que a confiabilidade das estimativas tenha um incremento maior com o uso de dados de topografia com maior resolução (30' de arco) para alimentar o modelo.

O estudo mostra a dificuldade de utilizar modelos numéricos de previsão de tempo para estimar ou prever a disponibilidade de energia eólica em uma região específica e a importância de conhecer os fenômenos locais e a interação destes com a dinâmica global da atmosfera.

\section{AGRADECIMENTOS}

Os autores agradecem ao CNPq pela concessão dos auxílios 55764/2010-9, e das bolsas de pesquisa 303904/2011-9 (FRM), 550990/2011-9 (EPB) e 303720/2010-7 (GF). Os autores agradecem à ELETROBRAS pela permissão de uso dos dados coletados em Roteiro e Girau do Ponciano no estado de Alagoas.

\section{REFERÊNCIAS BIBLIOGRÁFICAS}

AMARANTE, O. A. C.; BROWER, M.; ZACK, J.; DE SÁ, A. L. Atlas do Potencial Eólico Brasileiro. Brasília, p. 45,2001 .

BORBA, B. S. M. C.; LUCENA, A. F. P.; RATHMANN, R.; COSTA, I. V. L.; NOGUEIRA, L. P. P.; ROCHEDO, P. R. R.; CASTELO BRANCO, D. A.; JÚNIOR, M. F. H.; SZAKLO, A.; SCHAEFFER, R. Energy-related Climate Change Mitigation In Brazil: Potential, Abatement Costs and Associated Policies. Energy Policy, v.49, p. 430-441, 2012.

BROWN, K. B. Wind Power In Northeastern Brazil: Local Burdens, Regional Benefits And Growing Opposition. Climate and Development, v.3, p. 344-360, 2011.

CLIMANÁliSE. Boletim de Monitoramento e Análise Climática. Vol. $23-\mathrm{N}^{\circ} 05$ - Maio/2008. Disponível em $<$ http://climanalise.cptec.inpe.br/ rclimanl/boletim/>.

COSTA, G. B.; LYRA, R. Análise dos padrões de vento no estado de Alagoas. Revista Brasileira de Meteorologia, v.27, n 1, p.31-38, 2012.

DE MARIA, P. H. S.;COSTA, A. A.;SOMBRA, S. S. Modelagem Numérica em Alta Resolução para Previsão de Geração de Energia Eólica no Ceará. Revista Brasileira de Meteorologia, v. 23, n 4, p. 477-489, 2008.

ELETROBRÁS. Atlas eólico do estado de Alagoas.v.1, p. 67, 2008.

EPE. Nota Técnica DEA 01/11 - Manual do Usuário do Sistema de Acompanhamento de Medições Anemométricas AMA. Ministério de Minas e Energia. Empresa de Pesquisa Energética. Brasília: MME/EPE, 2011.
EPE. Plano Decenal de Expansão de Energia 2019. Ministério de Minas e Energia. Empresa de Pesquisa Energética. Brasília, MME/EPE, 2010.

FAO/UNESCO, Soil Mapof the World, 1988. Revised Legend, with corrections. Technical Paper 20. Reprint of World Soil Resources Report 60, FAO, Rome, 1988.

FAZENDA, A. L.; MOREIRA, D. S; ENARI, E. H.; PANETTA, J.; RODRIGUES, L.F. First Time User's Guide (BRAMS Version 4.0).CPTEC, v. 5, p. 30, 2007.

GOIS, G. de; SOUZA, J. L. de; SILVA, P. R. T. da; OLIVEIRA JÚNIOR, J. F. de. Caracterização da desertificação no estado de Alagoas utilizando variáveis climáticas. Revista Brasileira de Meteorologia, v. 20, n. 3, p. 301 - 314, 2005. GOldemberG, J.; VILlanueVA, L. D. Energia, Meio Ambiente \& Desenvolvimento. $3^{\circ}$ ed., p. 399, Editora USP, São Paulo, 2003.

GRELL, G.A.; DEVENYI, D.A generalized approach to parameterizing convection combining ensemble and data assimilation techniques. Geophysical Research Letters, v. 29, p. 38, 2002. doi:10.1029/2002GL015311

GRUBB, M.J.; MEYER, N.I. Wind Energy: Resources, Systems and Regional Strategies. In: JOHANSSON, T.B.; KELLY, H.; REDDY, A.; WILLIAMS, R. Renewable Energy: Sources for Fuels and Electricity. Washington, D. C. Islan Press, 1993.

IPCC. Intergovernmental Panel on Climate Change: Renewable Energy Sources and Climate Change Mitigation. Special Report of the Intergovernmental Panel on Climate Change. Cambridge University Press, 2011.

KAYANO, M. T.; ANDREOLI, R. V. Clima da região Nordeste do Brasil. In: Iracema F. A. Cavalcanti et al. (orgs). Tempo e Clima no Brasil, São Paulo: Oficina dos Textos, p. 213$233,2009$.

LIMA, F. J. L.; CAVALCANTI, E. P.; de SOUZA, E. P.; SILVA, E. M. Evaluation of the Wind Power in the State of Paraiba Using the Mesoscale Atmospheric Model Brazilian Developments on the Regional Atmospheric Modelling System. Renewable Energy, p. 16, 2012. doi:10.5402/2012/847356.

LIRA, M. A. T.; SILVA, E. M. da; ALVES, J. M. B. Estimativa dos recursos eólicos no litoral cearense usando a teoria da regressão linear. Revista Brasileira de Meteorologia, v.26, n. 3, p.349-366, 2011.

MARTINS, F. R.; GUARNIERI, R. A.; PEREIRA, E. B. O aproveitamento da energia eólica. Revista Brasileira de Ensino de Física, v.1, p. 13, 2008.

MARTINS, F. R.; PEREIRA, E. B. Enhancing information for solar and wind energy technology deployment in Brazil. Energy Policy, v.39, p.4378-4390, 2011.

MEASNET. MEASNET Procedure: Evaluation of site-specific wind conditions. v. 1., 2009. 
MELLOR, G.L.; YAMADA, T. Development of a turbulence closure model for geophysical fluid problems. Rev. Geophys Space Phys. v. 20, p. 851-875,1982.

MOLION, L. C. B.; BERNARDO, S. O. Uma revisão da dinâmica das chuvas no Nordeste Brasileiro. Revista Brasileira de Meteorologia, v. 17, n. 1, p.10, 2002.

MONTEIRO, C.; BESSA, R.; MIRANDA, V.; BOTTERUD, A.; WANG, J.; CONZELMANN, G. Wind Power forecasting: State-of-the-art 2009.Argonne: Argonne National Laboratory, 2009.

PEREIRA, E. B. O desafio das energias renováveis e suas implicações ambientais. Boletim da Sociedade Brasileira de Meteorologia, v. 30, p. 36-47, 2007.

PEREIRA, E. B.; MARTINS, F. R.; ABREU, S. L.; RUTHER, R.; AMARANTE, O.; CHAN, C.S.; LIMA, E. Solar and Wind Energy Brazilian Report.Instituto Nacional de Pesquisas Espaciais (INPE), São José dos Campos/SP, v.1, p. 100, 2008.

PROBST, O.; CARDENAS, D. State of the Artand Trends in Wind Resource Assessment. Energies, v 3, p. 1087-1141, 2010.

RAMOS, D. N. S.; LYRA, R. F. DA F.; SILVA JUNIOR, R. $\mathrm{S}$. Previsão do vento utilizando o modelo atmosférico WRF para o Estado de Alagoas. Revista Brasileira de Meteorologia, v. 28, n. 2, p.163-172, 2013.

SILVA, B. F. P. da; FEDOROVA, N.; LEVIT, V.; PERESETSKY, A.; BRITO, B. M. de. Sistemas Sinóticos associados as precipitações intensas no estado de Alagoas. Revista Brasileira de Meteorologia, v. 26, n. 3, p. 323 - 338, 2011.

SILVA, N. F.; ROSA, L. P.; ARAUJO, M. R. The utilization of Wind energy in the Brazilian electric sector expansion. Renewable and Sustainable Energy Reviews, v.9, p. 289-309, 2005.

SOUZA, D. O. de. Influência da ilha de calor urbana das cidades de Manaus e Belém sobre o microclima local. Tese (Doutorado em Meteorologia) Instituto Nacional de Pesquisas Espaciais (INPE), São José dos Campos/SP. p. 232, 2012.
SOUZA, E.P. Estudos teóricos e numéricos da relação entre conveç̧ão e superfície heterogêneas na região Amazônica. Tese (Doutorado em Meteorologia), Universidade de São Paulo (USP), São Paulo/SP. p. 121, 1999.

TOON, O.B.; MCKAY, C.P.; ACKERMAN, T.P.; SANTHANAM, K. Rapid calculation of radiative heating rates and photo dissociation rates in inhomogeneous multiple scattering atmospheres. Journal Geophys. Res., v. 94, p. 16287-16301, 1989.

VENDRAMINI, E. Z. Distribuições probabilísticas de velocidades do vento para avaliação do potencial energético eólico. Tese (Doutorado em Agronomia). Curso de Pós-Graduação em Agronomia, Faculdade de Ciências Agronômicas, Universidade Estadual Paulista (UNESP). Botucatu/SP. p. 110, 1986.

WALKO, R. L.; BAND, L. E.; BARON, J.; KITTEL, T. G. F.; LAMMERS, R.; LEE, T. J.; OJIMA, D.; PIELKE Sr, R. A.; TAYLOR, C.; TAGUE, C.; TREMBACK, C. J.; VIDALE, P. L. Coupled Atmosphere-Biophysics-Hydrology Models for Environmental Modeling. Journal of Applied Meteorology, v.39, n.6, p.931-944, 2000.

WALKO, R.L.; COTTON, W.R.; MEYERS, M.P.; HARRINGTON, J.Y. New RAMS cloud microphysics parameterization part I: the single-moment scheme. Atmospheric Research, v.38, n.1, p.29-62, 1995.

WILBANKS, T. J.; BHATT, V.; BILELLO, D. E.; BULL, S. R.; EKMANN, J.; HORAK, W. C.; HUANG, Y. J.; LEVINE, M. D.; SALE, M. J.; SCHMALZER, D. K.; SCOTT,M. J. Effects of Climate Change on Energy Production and Use in the United States. Report by the U.S. Climate Change Science Program and Global Change Research. Washington, DC, 2008.

WILKS, D.S. Statistical Methods In The Atmospheric Sciences. Academic Press, 676 p. 2011. 